\title{
Olfactory function in patients with hyposmia compared to healthy subjects - An fMRI study*
}

\author{
Robert Pellegrino ${ }^{1 *}$, Antje Hähner ${ }^{1}$, Viola Bojanowski ${ }^{1}$, Cornelia Hummel', \\ Johannes Gerber², Thomas Hummel'
}

Rhinology 54: 374-381, 2016

DOI:10.4193/Rhino16.098

*Received for publication:

March 6, 2016

Accepted: May 15, 2016

\begin{abstract}
Background: Individuals with hyposmia, or the partial loss of smell, represent a large sector (15\%) of the population that is likely to grow with the current aging population; however, our understanding to how hyposmics centrally process odors is still not clear. One popular non-invasive tool for in vivo imaging of biological activity among human brains has been function magnetic resonance imaging (fMRI) which uses blood-oxygenation level dependent (BOLD) signal as an indirect measurement. Therefore, the aim of this study was to understand differences in olfaction processing between patients with hyposmia and healthy controls using functional magnetic resonance imaging (fMRI).
\end{abstract}

Methodology: Eleven hyposmic and 12 healthy, normosmic subjects were exposed to two different food-related odors (coffee and peach) during a block-designed fMRI session. Additionally, odor perception qualities were rated for each odor throughout the scanning session.

Results: The activations of the normosmic group were localized in typical olfactory areas (insula, orbitofrontal cortex [OFC], limbic system and amygdala). The hyposmic group showed similar regions of activation (insula, OFC, limbic system), however, less activation was found in the amygdala, left anterior cingulate and right OFC, but higher activation was shown in the right parahippocampal and both the left and right posterior cingulate gyrus which are assumed to play an important role in the processing and remembrance of memories.

Conclusions: These results indicate similar central olfactory processing among groups, yet subjects with partial loss may attempt to compensate smell impairment with odor memory or higher motivation to smell.

Key words: olfactory, hyposmia, memory, fMRI, clinical

\section{Introduction}

Anosmia is the inability to perceive odors or lack of olfactory function. A less studied olfactory disorder is hyposmia which is the partial loss of smell. In total, about $5 \%$ of the population exhibit anosmia and approximately $15 \%$ are considered hyposmic while this number increases when considering specific impairment in detection, recognition and identification ${ }^{(1-4)}$. Furthering the understanding of olfaction, prevalence of loss of smell and risk factors: a population-based survey). This diminished sense of smell can be attributed to several factors including demographics, brain morphology and physiological responses. For instance, several studies have shown that olfactory loss increases as age increases with $50 \%$ of individuals over 65 years of age showing olfactory impairment ${ }^{(1,5)}$. Diseases associated with olfactory functionality may also contribute to the age-related impairment; for instance, the majority of hyposmic cases can be classified by inflammation of the nose and paranasal sinuses ${ }^{(6)}$ while other, less frequent hyposmic cases may be psychiatric (7), or neurodegenerative ${ }^{(8-10)}$.

Common techniques to examine the morphology and cerebral processing of olfactory information include EEG-derived eventrelated potentials ${ }^{(11,12)}$, positron emission tomography, $\mathrm{PET}^{(13)}$, 
computed tomography / magnetic resonance imaging, CT / MRI ${ }^{(14-18)}$ and functional MRI ${ }^{(12,19)}$. Using CT and MRI, studies have been able to determine differences in structural components such as the olfactory bulb and the olfactory sulcus that correlate with olfactory impairment ${ }^{(14-20)}$. Several fMRI studies have been able to further identify these olfactory process differences in individuals with neurodegenerative diseases ${ }^{(21,22)}$, while only a few studies have concentrated on differences between individuals with olfactory deficiencies due to other causes ${ }^{(12,23)}$. Therefore, more research to determine differences in central olfactory processing among typical hyposmic patients and healthy individuals is needed. In this study, we use psychophysical tests (e.g. "Sniffin'Sticks") to create two balanced groups, individuals with healthy (normosmic) and decreased (hyposmic) olfactory functionality. Participants were additionally screened for potential other causes of olfactory function loss, excluding patients with neurological disease and patents with olfactory loss due to acute or chronic inflammation of the nose and paranasal sinuses. Olfactory processing was measured using fMRI while two pleasant, food-related odors were sampled with odor perception being evaluated in-between stimuli.

\section{Materials and methods}

\section{Subjects and stimuli}

A total of 23 subjects participated in the study. Eleven women with an age range 42 to 71 years (mean age \pm SD $=59.6 \pm 8.9$ years) had hyposmia (determined from the TDI scores, see psychophysical measures). The remaining normosmic control group consisted of five women and seven men with an age range of 47 to 69 years ( $55.5 \pm 6.0$ years). None of the women were pregnant, and none of the participants had significant health problems (e.g. kidney failure) currently or in medical history that may be associated with disorders of olfactory function. Furthermore, each underwent a standard ENT examination with endoscopy and individuals with polyps, acute or chronic inflammation of the nose, paranasal sinuses, or major septum deviations were excluded from the study. All subjects were right-handed as established by means of the Edinburgh Inventory ${ }^{(24)}$. Additionally, subjects reported no claustrophobia and were able to undergo MRI examinations. The study design met the requirements of the Declaration of Helsinki and had been approved by the Ethics Committee of the Medical Faculty Carl Gustav Carus at the Technical University of Dresden.

After examining the medical history and assessment of olfactory functionality, each subject was informed of the testing procedures, specifically MRI procedures, and gave written informed consent. In the MRI scanner, the endings of odor dispensing cannulas (4-mm inner diameter) were placed in the subjects' nostril. The odor delivery was carried out by an olfactometer positioned in a neighboring room. For stimulation, the two odors chosen

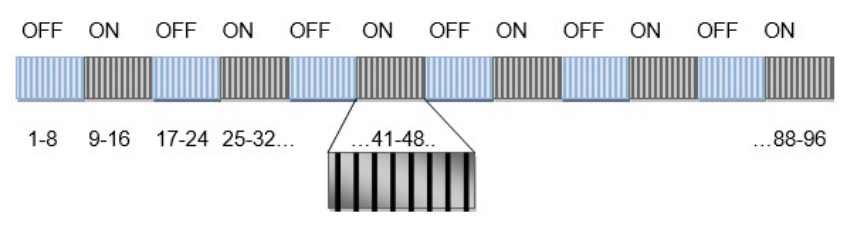

Figure 1. Represent the schematically structured passage of MRI scan. This consisted of $6 \mathrm{ON}$ - (with odor delivery) and 6 OFF-blocks (without odor delivery). In each block, 8 scans were held. Therefore, 96 scans were performed in a single pass.

were peach and coffee (Pfirsich-Aroma, Kaffee-Aroma; Frey und Lau, Henstedt-Ulzburg, Germany) while water was used as a control. Odors were chosen since they are familiar to at least $75 \%$ of the German population. Clean air (from hospital resources) was passed at $2 \mathrm{~L}$ / min via a pulse generator for odor presentation to the subject. The pulse generator was set at a pulse length of 1 second at interstimulus intervals (ISIs) of two seconds; odors were presented for a period of $20 \mathrm{~s}$ (ON period), with intervals of $20 \mathrm{~s}$ (OFF period) where only odorless air was presented (Figure 1). Both stimulus qualities (coffee and peach) were presented in undiluted concentrations clearly perceivable and without causing any trigeminal sensation.

The fMRI study began with a "shim" sequence to counter the effect of magnetic field inhomogeneity ${ }^{(25)}$. This was followed by six odor (ON) and no-odor (OFF) blocks of scanning with each block consisting of 8 scans. In each run, only one scent (coffee or peach) was used and the stimulus was directed to only one nostril (left or right), again, in order to make the sessions more interesting to the participants and also to minimize adaptation to the odors. Thus, 96 scans were performed per odor on each nostril, and the order of runs was randomized for each subject. After each run subjects were asked to identify the presented odor. Odor identification answers within the same category as the odor presented (e.g. fruit for peach or cappuccino for coffee) were counted as correct. In addition, subjects were asked to rate the intensity (0 to $10 ;$ "Not perceived" to "Very strongly perceived") and valence (-5 to 5 ; "Extremely unpleasant" to "Extremely pleasant"). As mentioned above, none of the subjects reported a stinging or burning sensation in response to odorous stimulation. After all fMRI runs had been completed, brain anatomy scans were taken for anatomical correlation.

\section{Psychophysical measures}

A test of orthonasal olfactory function was carried out using pen-like odor dispensers called "Sniffin' Sticks". "Sniffin' Sticks" were used to test three different olfactory functions: olfactory threshold (phenyl ethyl alcohol), odor discrimination and odor identification. Results of the 3 subtests were presented as a composite score for threshold, discrimination, and identification (TDI 
score) which was then used to classify olfactory function groups for the study, hyposmia or normosmia (control) according to the age-matched normative data ${ }^{(11,26)}$.

\section{fMRI scanning parameters}

A 1.5 T MRI scanner (Siemens Sonata, Erlangen, Germany) and a full-head eight-channel receiver coil were used for image acquisition. A gradient echo T2*-sensitive echo planar imaging (GE-EPI) sequence was employed (TR 2500 ms, TE 40 ms, image matrix $64 \times 64$, in-plane resolution $3 \mathrm{~mm}$, through-plane resolution $3.75 \mathrm{~mm}$ ). The time of echo was selected because it had been established for 1.5 Tesla scanners for the imaging of limbic structures ${ }^{(27)}$. Images were acquired in the axial plane oriented parallel to the planum sphenoidale to minimize artifacts. A total of 96 functional volumes per run in twenty-six slice locations (covering the entire head) were acquired per session. A full brain T1-weighted turbo FLASH 3D-sequence was acquired to overlay functional data (TR 2200, TE 3.93, slice thickness: 1 mm).

\section{fMRI data processing}

Data was analyzed using SPM8 (www.fil.ion.ucl.ac.uk/spm) in the Matlab framework (Matlab 6.5 R3, The MathsWorks Inc., Natick, MA, USA). Functional data was motion corrected and coregistered with the anatomical images. Segmentation of the latter into white and grey matter compartments yielded parameters for normalization with respect to the MNI space. Finally, functional normalized data was smoothed with an $8 \times 8 \times 8 \mathrm{~mm}^{3} \mathrm{FWHM}$ Gaussian kernel.

First level analysis was carried out with the standard canonical hemodynamic response function used in SPM 8. Contrast images for "odor ON > odor OFF (modeled baseline)" were generated for each subject. In second level analysis, these images were subjected to a random effect analysis using 1) independent sample t-test for within olfactory group comparisons of On and Off conditions and 2) a $3 \times 2$ factorial design with olfactory group as a between subject and odorant and site specific activation as within subject factors. To evaluate bi-directional main effects between groups, results of the one-sample t-tests are reported with a threshold of $p<0.001$, uncorrected. Furthermore, main effects between olfactory groups underwent ROI analysis for areas relevant to olfactory processing (piriform cortex, amygdala, thalamus, hippocampus, insula, orbito-frontal cortex). All masks were created using the "automated anatomical labeling (aal)" atlas (28), embedded in WFU PickAtlas 2.4 software ${ }^{(29)}$, except for the piriform cortex (defined according to the criteria described in ${ }^{(30)}$ and the hypothalamus (6-mm sphere around $(-6|0|-14)^{(31)}$. For ROI analysis, thresholds were set at $p<0.05$, corrected with a cluster criterion of five voxels for whole brain analysis and Bonferroni-corrected for multiple comparisons of the eight ROIs $(p<0.05 / 8=0.006)$ with a cluster criterion of (a)
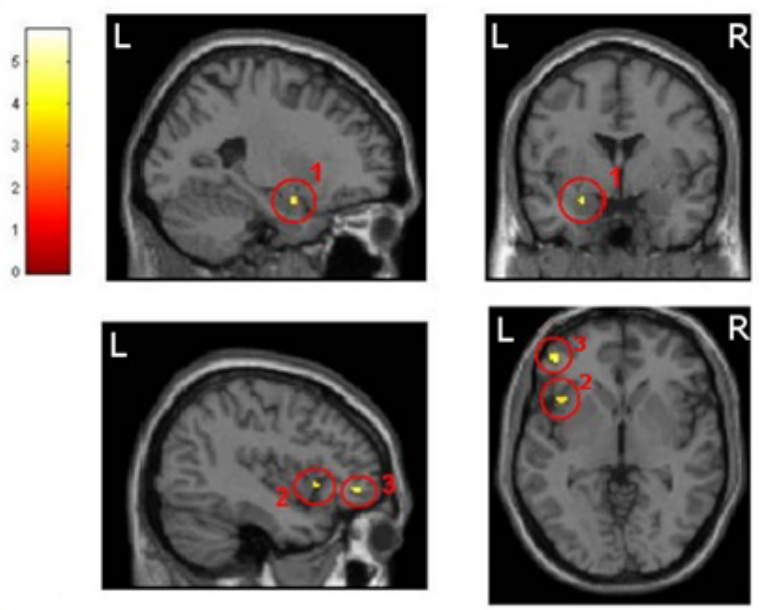

(b)
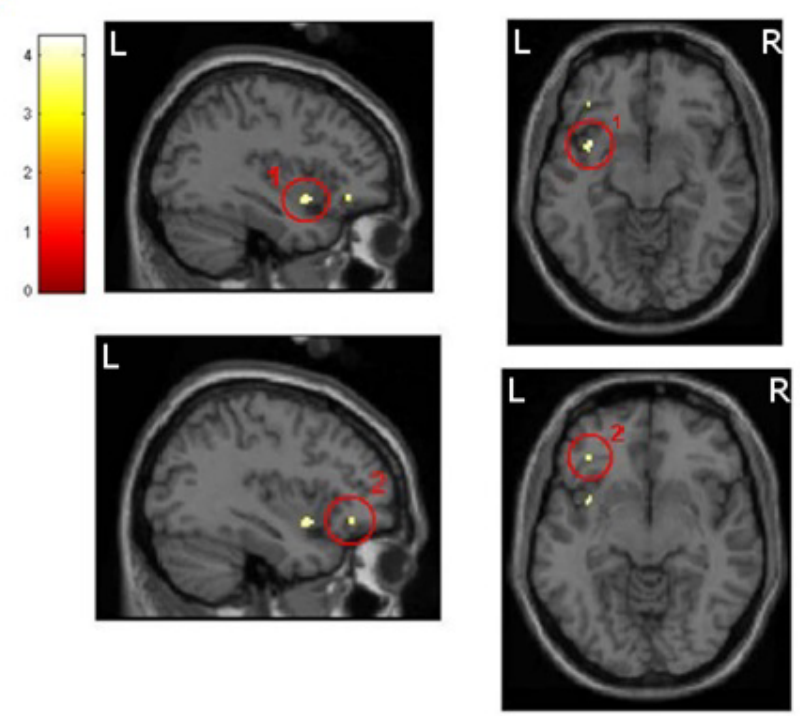

Figure. 2 (a) Odor vs. non-odor for normosmic subjects: The Figure shows an activation of the left amygdala, the left insula and left OFC under the stimulus condition. The red ring 1 marks the voxel clusters in the left amygdala (coordinates: $x:-24 m m, y: 0 \mathrm{~mm}, \mathrm{z}:-20 \mathrm{~mm}$ ), ring 2 in the left insula (coordinates: $x:-16 \mathrm{~mm}, \mathrm{y}: 16 \mathrm{~mm}$, eg: $-2 \mathrm{~mm}$ ) and ring 3 in the left OFC (coordinates: $x:-44 m m, y: 46 m m, z:-4 m m)$. The scale represents the t-value of the voxel clusters and defines the color of the cluster (with mask, $\mathrm{p}<0.001, \mathrm{Vox} / \mathrm{Cl}>5$ ) (b) Odor vs. non-odor for hyposmic subjects: The figure shows an activation of the left insula and left OFC. Ring 1 marks the voxel clusters in the left Insulation (coordinates: $x$ : - 36mm, y: $8 \mathrm{~mm}$ z: $10 \mathrm{~mm}$ ) and ring 2 in the left OFC (coordinates: $x$ : $-36 \mathrm{~mm}, \mathrm{y}: 34 \mathrm{~mm}$, for example: - $8 \mathrm{~mm}$ ). The scale represents the t-value of the voxel clusters and also defines the color of the cluster. (with mask $1 ; \mathrm{p}<0.001$, Vox $/ \mathrm{Cl} \geq 5$ ).

five voxels.

\section{Results}

Psychophysical measures 
(a)
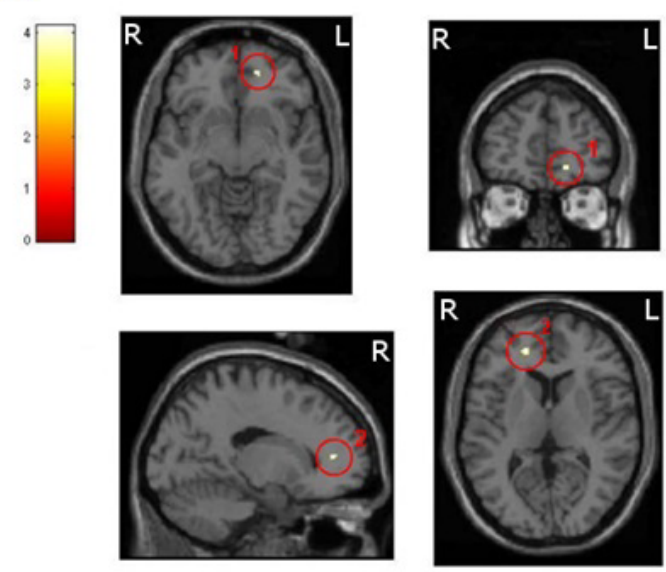

(b)
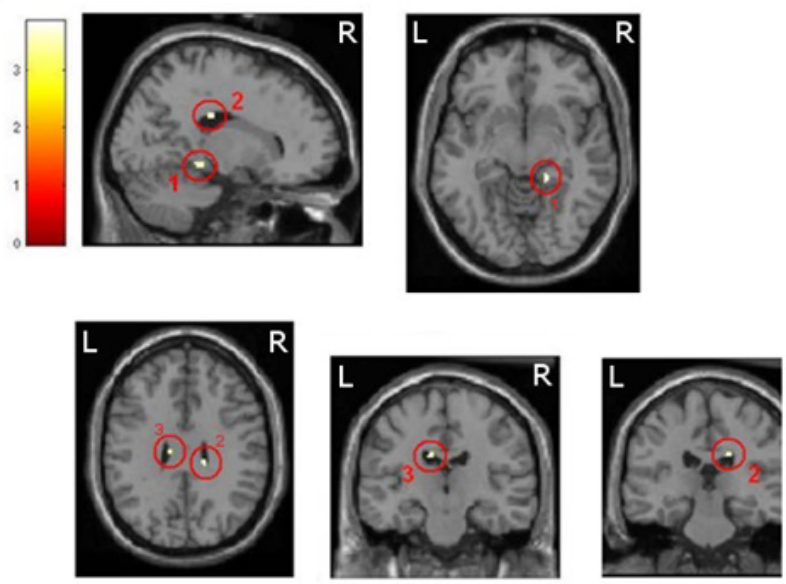

Figure. 3 (a). Normosmic against hyposmic subjects: The Figure shows larger activations in the left anterior cingulate and right OFC for normosmic subjects. The red ring 1 marks the voxel clusters in the left limbic sheet (coordinates: $x:-18 \mathrm{~mm}, \mathrm{y}: 44 \mathrm{~mm}$, for example: $8 \mathrm{~mm}$ ) and the ring 2 in the right OFC (coordinates: $x: 16 \mathrm{~mm} y: 48 \mathrm{~mm}$, e.g. : $-8 \mathrm{~mm}$ ). The scale represents the $t$-value of the voxel clusters and also defines the color of the cluster (with mask, $\mathrm{p}<0.001$, Vox $/ \mathrm{Cl} \geq 5$ ). (b). Hyposmic against normosmic subjects: The Figure shows larger activations in three areas of the cingulate cortex for hyposmic subjects. The red ring 1 marks the voxel clusters in the right parahippocampal gyrus (coordinates: $\mathrm{x}: 18 \mathrm{~mm}, \mathrm{y}:-36 \mathrm{~mm}$, eg: $-8 \mathrm{~mm}$ ), ring 2 in the right posterior cingulate gyrus (coordinates: $x: 18 \mathrm{~mm}, \mathrm{y}:-26 \mathrm{~mm}, \mathrm{eg}: 30 \mathrm{~mm}$ ) and ring 3 in the left posterior cingulate gyrus (coordinates: $x: 12 \mathrm{~mm}, \mathrm{y}:-18 \mathrm{~mm}$, eg $28 \mathrm{~mm}$ ). The scale represents the $\mathrm{t}$-value of the voxel clusters and also defines the color of the cluster. (with mask, $\mathrm{p}<0.001$, Vox $/ \mathrm{Cl} \geq 5$ ).

As shown in Table 1, normosmic and hyposmic groups differed significantly in the composite TDI score, and its constituent tests - threshold, discrimination and identification. For instance, the mean (SD) TDI score for the control group was 33.81 (3.72) compared to hyposmic subjects who scored 19.50 (4.77) while the threshold and identification showed the largest difference between the olfactory groups. For hyposmic subjects, the most frequent cause of olfactory dysfunction was viral $(n=6)$ followed by idiopathic $(n=4)$ and traumatic $(n=1)$.

\section{Evaluation of odors during the fMRI sessions \\ Between odors, peach was identified significantly more often than coffee among normosmic subjects ( $<0.001)$. Additionally, peach and coffee were identified correctly significantly more by normosmic subjects (58 \% and $38 \%$, respectively) than hypos- mic subjects ( $9 \%$ for both odors) $(p<0.001)$. The peach odor was also more intense among normosmic than hyposmic subjects ( $p<0.001$ ). Additionally, normosmic subjects rated both peach and coffee significantly more pleasant than the hyposmic group ( $p=0.01$ and $p=0.02$, respectively).}

\section{Neuroimaging results}

Comparing the odor (ON) and non-odor (OFF) blocks during runs (Figure 2), hyposmic subjects showed significantly less and weaker brain activations than for the normosmic subjects. Normosmic subjects showed significant differences between odor and non-odor blocks in the left insula, left amygdala, and left orbital frontal cortex (OFC), with the largest activations in the OFC (39 Vox / Cl). In contrast, hyposmic subjects showed significant differences between block conditions in the left OFC and left insula, with the largest activation in the insula (18 Vox / Cl). In a direct comparison (Figure 3), normosmic participants showed higher activations than hyposmic subjects in olfactory regions such as the left anterior cingulate and right OFC. However, hyposmic subjects showed larger activation in three areas of the limbic system; the right posterior cingulate gyrus, left posterior cingulate gyrus and the right parahippocampal gyrus. For more details on activation differences within and between patient comparisons see Table 2 .

\section{Discussion}

As expected, healthy subjects showed brain activity in regions that are associated with olfactory processing such as the amygdala, OFC, insula and limbic system. This observation confirms several PET and $\mathrm{fMRI}$ studies that show similar regions activated during odor stimulation ${ }^{(32-35)}$. Hyposmic subjects showed activations for similar brain regions such as the left insular and OFC; however, these activations were substantially weaker. Decreased activations may be due to decreased olfactory perception, where hyposmic subjects were only able to identify both odors $10 \%$ of the time and intensity ratings were much lower than in healthy subjects. Similarly, Levy et al. ${ }^{(23)}$ presented three odors (pyridine, menthone, and amyl acetate) to eight patients with hyposmia during an fMRI paradigm. In comparison to 17 healthy subjects undergoing similar studies, they showed that brain activation was lower in each section of the olfactory cortex in hyposmic patients, varying one-third to one-half that of normal 
Table 1. Characteristics of hyposmia and normosmia groups (mean $\pm \mathrm{SD}$ ).

\begin{tabular}{|c|c|c|c|c|c|c|c|}
\hline $\begin{array}{l}\text { Olfactory } \\
\text { Group }\end{array}$ & Age (years) & $\begin{array}{c}\text { Olfactory } \\
\text { Impairment (N) }\end{array}$ & Impairment & TDI & $\begin{array}{c}\text { Threshold } \\
\text { (T) }\end{array}$ & $\begin{array}{l}\text { Discrimination } \\
\text { (D) }\end{array}$ & $\begin{array}{l}\text { Identification } \\
\text { (I) }\end{array}$ \\
\hline Hyposmia & $59.64 \pm 8.86$ & $\begin{array}{c}\text { Post-viral (6) } \\
\text { Idiopathic (4) } \\
\text { Post-traumatic (1) }\end{array}$ & duration (years) & $19.50 \pm 4.77$ & $3.23 \pm 1.77$ & $9.45 \pm 2.34$ & $6.82 \pm 1.72$ \\
\hline Normosmia & $55.50 \pm 5.95$ & - & - & $33.81 \pm 3.72$ & $8.81 \pm 2.25$ & $12.00 \pm 2.04$ & $13.00 \pm 1.21$ \\
\hline
\end{tabular}

Table 2. Comparison between blocks and patient groups for healthy and hyposmic subjects.

\begin{tabular}{|c|c|c|c|c|c|c|c|c|c|c|}
\hline \multicolumn{11}{|c|}{ Between Blocks (Odor - No Odor) } \\
\hline \multirow[b]{2}{*}{ Brain Areas (Hemisphere) } & \multicolumn{5}{|c|}{ Normosmia } & \multicolumn{5}{|c|}{ Hyposmia } \\
\hline & $\mathbf{x}$ & $y$ & $\mathbf{z}$ & Voxel & t-score & $\mathbf{x}$ & $\mathbf{y}$ & $\mathbf{z}$ & Voxel & t-score \\
\hline Orbital frontal cortex (L) & -44 & 46 & -4 & 39 & 5.75 & -36 & 34 & -8 & 6 & 3.50 \\
\hline Amygdala (L) & -24 & 0 & -20 & 7 & 3.87 & - & - & - & - & - \\
\hline Insula (L) & -40 & 16 & -2 & 9 & 3.68 & -36 & 8 & -10 & 18 & 4.31 \\
\hline Parahipppocampal gyrus (L) & -26 & -52 & 4 & 8 & 3.66 & -16 & -12 & 40 & 5 & 3.67 \\
\hline \multirow[t]{2}{*}{ Inferior frontal gyrus (L) } & -40 & 24 & -16 & 6 & 3.67 & - & - & - & - & - \\
\hline & \multicolumn{10}{|c|}{ Between Groups } \\
\hline Anterior cingulate $(\mathrm{L})$ & -18 & 44 & 8 & 14 & 3.98 & - & - & - & - & - \\
\hline Orbital frontal cortex (R) & 16 & 48 & -8 & 6 & 3.72 & - & - & - & - & - \\
\hline Parahipppocampal gyrus (R) & - & - & - & - & - & 18 & -36 & -8 & 10 & 3.83 \\
\hline Parietal cingulate (L) & - & - & - & - & - & -12 & -18 & 28 & 8 & 3.63 \\
\hline Parietal cingulate (R) & - & - & - & - & - & 18 & -26 & 30 & 15 & 3.60 \\
\hline Precuneus (R) & - & - & - & - & - & 6 & -52 & 10 & 5 & 3.54 \\
\hline
\end{tabular}

subjects, and significant mean activation differences were gathered for six of the nine individual brain sections studied. Additionally, their study showed forward processing activation centers of the CNS such as the frontal and temporal cortex were much less activated or even with no activation in patients compared to normal subjects. Our study supports these observations with a direct comparison of healthy and hyposmic patients. An explanation for differences could be structurally related in which various volumetric changes in the brain may explain some of the reduction of stimulus response in higher processing functions. For instance, several studies have shown that reduced olfactory function may be associated with a reduction of olfactory bulb volume and that this structural reduction is more pronounced the longer an olfactory disorder persists ${ }^{(15,16,18,36,37)}$. Reduced olfactory perception, and thus reduced odor pleasantness and intensity, may also explain the absence of amygdala activations in hyposmic patients ${ }^{(38)}$.

Direct comparison of the two subject groups provides more detail into odor processing similarities and differences. Overall, all subjects showed similar areas of activation since both groups still had a sense of smell although functioning at different levels. However, healthy subjects showed larger activation in the central olfactory processing areas right OFC and left cingulate. Similarly, other studies have shown reduced response within the frontal areas and cingulate regions of the limbic system when comparing hyposmic and healthy subjects ${ }^{(23)}$. Furthermore, in our study hyposmic subjects showed significantly more activation across the posterior cingulate and the surrounding regions. This brain region is highly involved in memory-odor associations which are formed in adolescence and remembered over a long time ${ }^{(39-41)}$. In this study, the average duration of olfactory dysfunction was around 2 years, raising the point that subjects had ample time to associate odors with memory and these memoryodor associations may be used more frequently to compensate for olfactory loss. For instance, Levy et al. ${ }^{(42)}$ asked 21 normal subjects to imagine odors of banana and peppermint and then actually smell the corresponding odors while using multislice FLASH MRI to measure their responses. Anterior to posterior 
temporal brain regions were activated for both imagined and actual odors were present; however, imagined odors showed less activation than the response to the actual odor. Additionally, this study performed the same test with two subjects with hyposmia that showed an opposite trend where imagined odors had higher activations than the actual odors. Thus, this anecdotal report indicates that the retrieval of odor memories in the expectation of an odor could constitute higher memory processing while underperforming in olfactory processing. More specifically, the right parahippocampal gyrus $(\mathrm{PHC})$ is involved in working memory and may be used as a temporary storage system for the entrance and retrieval of information from episodic memory, termed episodic buffer ${ }^{(43,44)}$. Arshamian et al. ${ }^{(41)}$ support this juncture that odor evoked autobiographical memories (OEAMs) result in more activity in the parahippocampus. Their study also showed increased activation from OEAMs in the precuneus which relates to visual vividness. Furthermore, hyposmics showed lateralized activation of the posterior cingulate gyrus and this brain region has consistently been activated during standard and autobiographical memory retrieval ${ }^{(45)}$. Similarly, the posterior cingulate has been associated with semantic memory processes and the strength of its BOLD response increases with continual rehearsal of episodic details to help create more vivid memories ${ }^{(46,47)}$. In our study, hyposmic patients were aware that an odor was being presented, and having partial loss, may have increased their engagement to explicitly recall the odor identity with past information. Therefore, motivational differences may exist between healthy and hyposmic patients with the later showing increase activation as a result of higher motivation to actively smell and identify an odor. For instance, a common psychophysical method to assess olfactory function is the University of Pennsylvania Smell Identification Test (UPSIT) which asks subject to scratch paper strips containing a microencapsulated odor and rate its intensity. Doty and colleagues ${ }^{(48)}$ analyzed the density of marking on 1680 such strips from tests administered to 42 anosmic, hyposmic and normosmic subjects and reported that hyposmic participants attempted to increase perceived intensity of odor by scratching the scent strips more vigorously than the other two groups. Findings from the present study add to the limited information concerning differences among individuals having partial loss of olfactory sense and their healthy counterpart; however, it is important to note limitations of this study. For instance, the hyposmic group under examination consisted of only women. In many psychophysical tests women have shown better olfactory function than men, regardless of age and ethnic background ${ }^{(3,5,49)}$ while several PET and MRI studies report no gender differences in activation areas of central olfactory processing ${ }^{(50-53)}$. Additionally, participants in both groups had an average age above 55 years. Here, despite the equal age distribution on both groups, a certain age effect is possible since olfactory performance declines as age increases ${ }^{(1,5,49)}$ including anatomical and physiological changes (e.g. volume of olfactory bulb or number of olfactory receptors) ${ }^{(54,55)}$. Lastly, a key limitation of this study is the hyposmics patients sampled were not homogenous in diagnosis (consisting of patients with olfactory loss due to trauma, viral infections and idiopathic causes). Due to these study caveats, results should be interpreted with some caution and additional studies should be performed to examine olfactory function of normal and hyposmic patients.

\section{Authorship contribution}

RP: data analysis and write up; $\mathrm{AH}$ : data analysis, help with write up; VB: draft of study, conduct all measurements, help with data analysis; $\mathrm{CH}$ : help with data analysis, help with write up; JG: help with data acquirement, technical help; TH: draft of study, help with write up.

\section{Conflict of interest}

None.

\section{References}

1. Murphy C. Prevalence of Olfactory Impairment in Older Adults. JAMA. American Medical Association; 2002 Nov 13;288(18):2307.

2. Brämerson A, Johansson L, Ek L, Nordin S, Bende M. Prevalence of olfactory dysfunction: the skövde population-based study. Laryngoscope. 2004 Apr;114(4):733-7.

3. Landis BN, Konnerth CG, Hummel T. A study on the frequency of olfactory dysfunction. Laryngoscope. 2004 Oct;114(10):1764-9.

4. Mullol J, Alobid I, Mariño-Sánchez F, Quintó $L$, de Haro J, Bernal-Sprekelsen $M$, et al. Furthering the understanding of olfaction, prevalence of loss of smell and risk factors: a population-based survey (OLFACAT study). BMJ Open. 2012 Jan 1;2(6)

5. Doty R, Shaman P, Applebaum S, Giberson
R, Siksorski L, Rosenberg L. Smell identification ability: changes with age. Science (80). 1984 Dec 21;226(4681):1441-3.

6. Damm M, Temmel A, Welge-Lüssen A, Eckel HE, Kreft M-P, Klussmann JP, et al. [Olfactory dysfunctions. Epidemiology and therapy in Germany, Austria and Switzerland]. HNO. 2004 Feb;52(2):112-20.

7. Moberg PJ, Agrin R, Gur RE, Gur RC, Turetsky BI, Doty RL. Olfactory dysfunction in schizophrenia: a qualitative and quantitative review. Neuropsychopharmacology. American College of Neuropsychopharmacology; 1999 Sep;21(3):325-40.

8. Doty RL, Deems DA, Stellar S. Olfactory dysfunction in parkinsonism: A general deficit unrelated to neurologic signs, disease stage, or disease duration. Neurology. 1988
Aug 1;38(8):1237-1237.

9. Müller $A$, Müngersdorf $M$, Reichmann $H$, Strehle G, Hummel T. Olfactory function in Parkinsonian syndromes. J Clin Neurosci. 2002 Sep;9(5):521-4.

10. Ponsen MM, Stoffers D, Booij J, van Eck-Smit BLF, Wolters EC, Berendse HW. Idiopathic hyposmia as a preclinical sign of Parkinson's disease. Ann Neurol. 2004 Aug;56(2):173-81.

11. Kobal G, Klimek L, Wolfensberger M, Gudziol $\mathrm{H}$, Temmel A, Owen CM, et al. Multicenter investigation of 1,036 subjects using a standardized method for the assessment of olfactory function combining tests of odor identification, odor discrimination, and olfactory thresholds. Eur Arch Oto-RhinoLaryngology. 2000 Apr 25;257(4):205-11.

12. Welge-Lüssen $A$, Wattendorf $E$, Schwerdtfeger U, Fuhr P, Bilecen D, Hummel 
T, et al. Olfactory-induced brain activity in Parkinson's disease relates to the expression of event-related potentials: a functional magnetic resonance imaging study. Neuroscience. 2009 Aug 18;162(2):537-43.

13. Bohnen NI, Gedela S, Herath P, Constantine GM, Moore RY. Selective hyposmia in Parkinson disease: association with hippocampal dopamine activity. Neurosci Lett. 2008 Dec 5;447(1):12-6.

14. Levy LM, Bartsch AJ, Rajan S, Schellinger D HH. MRI of olfactory structures: normal subjects and patients with olfactory dysfunction. In: Proceedings of the XV Symposium Neuroradiologicum. Berlin, Heidelberg: Springer Berlin Heidelberg; 1995. p. 25-6.

15. Mueller A, Rodewald A, Reden J, Gerber $J$, von Kummer R, Hummel T. Reduced olfactory bulb volume in post-traumatic and post-infectious olfactory dysfunction. Neuroreport. 2005 Apr 4;16(5):475-8.

16. Rombaux P, Duprez T, Hummel T. Olfactory bulb volume in the clinical assessment of olfactory dysfunction. Rhinology. 2009 Mar;47(1):3-9.

17. Bitter T, Brüderle J, Gudziol H, Burmeister HP, Gaser C, Guntinas-Lichius O. Gray and white matter reduction in hyposmic subjects--A voxel-based morphometry study. Brain Res. 2010 Aug 6;1347:42-7.

18. Rombaux P, Potier H, Markessis E, Duprez $T$, Hummel T. Olfactory bulb volume and depth of olfactory sulcus in patients with idiopathic olfactory loss. Eur Arch Oto-Rhino-Laryngology. 2010 Mar 19;267(10):1551-6.

19. Yousem DM, Geckle RJ, Bilker W, McKeown DA, Doty RL. MR evaluation of patients with congenital hyposmia or anosmia. AJR Am J Roentgenol. American Public Health Association; 1996 Feb 19;166(2):439-43.

20. Yousem DM, Turner WJ, Li C, Snyder PJ, Doty RL. Kallmann syndrome: MR evaluation of olfactory system. AJNR Am J Neuroradiol. 1993 Jul 1;14(4):839-43.

21. Hummel T, Fliessbach $K$, Abele M, Okulla T, Reden J, Reichmann H, et al. Olfactory FMRI in patients with Parkinson's disease. Front Integr Neurosci. 2010 Jan;4:125.

22. Barresi M, Ciurleo R, Giacoppo S, Foti Cuzzola V, Celi D, Bramanti P, et al. Evaluation of olfactory dysfunction in neurodegenerative diseases. J Neurol Sci. 2012 Dec 15:323(1-2):16-24.

23. Levy LM, Henkin RI, Hutter A, Lin CS, Schellinger D. Mapping Brain Activation to Odorants in Patients with Smell Loss by Functional MRI. J Comput Assist Tomogr. 1998 Jan 2;22(1):96-103.

24. Oldfield RC. The assessment and analysis of handedness: The Edinburgh inventory. Neuropsychologia. 1971 Mar;9(1):97-113.

25. Jezzard $\mathrm{P}$, Clare $\mathrm{S}$. Sources of distortion in functional MRI data. Hum Brain Mapp. 1999 Jan;8(2-3):80-5.

26. Hummel T, Sekinger $B$, Wolf SR, Pauli E, Kobal G. "Sniffin" Sticks': Olfactory Performance Assessed by the Combined
Testing of Odour Identification, Odor Discrimination and Olfactory Threshold. Chem Senses. 1997 Feb 1;22(1):39-52.

27. Stöcker T, Shah NJ. MP-SAGE: A new MP-RAGE sequence with enhanced SNR and CNR for brain imaging utilizing square-spiral phase encoding and variable flip angles. Magn Reson Med. 2006 Oct;56(4):824-34.

28. Tzourio-Mazoyer N, Landeau B, Papathanassiou D, Crivello F, Etard O, Delcroix N, et al. Automated anatomical labeling of activations in SPM using a macroscopic anatomical parcellation of the MNI MRI single-subject brain. Neuroimage. 2002 Jan;15(1):273-89.

29. Maldjian JA, Laurienti PJ, Kraft RA, Burdette $J H$. An automated method for neuroanatomic and cytoarchitectonic atlas-based interrogation of fMRI data sets. Neuroimage. 2003 Jul;19(3):1233-9.

30. Berglund $H$, Lindström $P$, Savic I. Brain response to putative pheromones in lesbian women. Proc Natl Acad Sci U S A. 2006 May 23;103(21):8269-74.

31. Zelano C, Bensafi M, Porter J, Mainland J, Johnson B, Bremner E, et al. Attentional modulation in human primary olfactory cortex. Nat Neurosci. Nature Publishing Group; 2005 Jan;8(1):114-20.

32. Zatorre RJ, Jones-Gotman M, Evans AC, Meyer E. Functional localization and lateralization of human olfactory cortex. Nature. 1992 Nov 26;360(6402):339-40.

33. Zald DH, Pardo J V. Emotion, olfaction, and the human amygdala: Amygdala activation during aversive olfactory stimulation. Proc Natl Acad Sci. 1997 Apr 15;94(8):4119-24.

34. Sobel N, Prabhakaran V, Desmond JE, Glover GH, Goode RL, Sullivan E V, et al. Sniffing and smelling: separate subsystems in the human olfactory cortex. Nature. 1998 Mar 19;392(6673):282-6

35. Zald DH, Pardo J V. Functional neuroimaging of the olfactory system in humans. Int J Psychophysiol. 2000 May;36(2):165-81.

36. Haehner A, Rodewald A, Gerber JC, Hummel T. Correlation of olfactory function with changes in the volume of the human olfactory bulb. Arch Otolaryngol Head Neck Surg. American Medical Association; 2008 Jun 1;134(6):621-4.

37. Goektas O, Fleiner F, Sedlmaier B, Bauknecht C. Correlation of olfactory dysfunction of different etiologies in MRI and comparison with subjective and objective olfactometry. Eur J Radiol. 2009 Sep;71 (3):469-73.

38. Winston JS, Gottfried JA, Kilner JM, Dolan RJ. Integrated neural representations of odor intensity and affective valence in human amygdala. J Neurosci. 2005 Sep 28:25(39):8903-7.

39. Chu S, Downes JJ. Long live Proust: the odour-cued autobiographical memory bump. Cognition. 2000 May;75(2):B41-50.

40. Herz RS. A Naturalistic Analysis of Autobiographical Memories Triggered by Olfactory Visual and Auditory Stimuli. Chem
Senses. 2004 Mar 1:29(3):217-24.

41. Arshamian A, lannilli E, Gerber JC, Willander J, Persson J, Seo H-S, et al. The functional neuroanatomy of odor evoked autobiographical memories cued by odors and words. Neuropsychologia. 2013 Jan;51(1):123-31.

42. Levy LM, Henkin RI, Lin CS, Hutter A, Schellinger D. Odor memory induces brain activation as measured by functional MRI. J Comput Assist Tomogr. 1999 Jan;23(4):48798.

43. Axmacher N, Schmitz DP, Weinreich I, Elger CE, Fell J. Interaction of working memory and long-term memory in the medial temporal lobe. Cereb Cortex. 2008 Dec 1;18(12):2868-78.

44. Luck D, Danion J-M, Marrer C, Pham B-T, Gounot D, Foucher J. The right parahippocampal gyrus contributes to the formation and maintenance of bound information in working memory. Brain Cogn. 2010 Mar;72(2):255-63.

45. Maddock R., Garrett A., Buonocore M. Remembering familiar people: the posterior cingulate cortex and autobiographical memory retrieval. Neuroscience. 2001 Jun;104(3):667-76.

46. Binder JR, Desai RH, Graves WW, Conant LL. Where is the semantic system? A critical review and meta-analysis of 120 functional neuroimaging studies. Cereb Cortex. 2009 Dec 1;19(12):2767-96.

47. Bird CM, Keidel JL, Ing LP, Horner AJ, Burgess N. Consolidation of Complex Events via Reinstatement in Posterior Cingulate Cortex. J Neurosci. 2015 Oct 28;35(43):14426-34.

48. Doty RL, Genow A, Hummel T. Scratch density differentiates microsmic from normosmic and anosmic subjects on the University of Pennsylvania Smell Identification Test. Percept Mot Skills. Ammons Scientific; 1998 Feb 31;86(1):2116.

49. Hummel T, Kobal G, Gudziol H, Mackay-Sim A. Normative data for the "Sniffin' Sticks" including tests of odor identification, odor discrimination, and olfactory thresholds: an upgrade based on a group of more than 3,000 subjects. Eur Arch Otorhinolaryngol. 2007 Mar;264(3):237-43.

50. Levy LM, Henkin RI, Hutter A, Lin CS, Martins D, Schellinger D. Functional MRI of Human Olfaction. J Comput Assist Tomogr. 1997 Nov 12;21(6):849-56.

51. Yousem DM, Maldjian JA, Siddiqi F, Hummel T, Alsop DC, Geckle RJ, et al. Gender effects on odor-stimulated functional magnetic resonance imaging. Brain Res. 1999 Feb;818(2):480-7.

52. Bengtsson S, Berglund H, Gulyas B, Cohen E, Savic I. Brain activation during odor perception in males and females. Neuroreport. 2001;323(1):16-25.

53. Savic I. Brain imaging studies of the functional organization of human olfaction. Chem Senses. 2005 Jan 1;30 Suppl 
1(suppl_1):i222-3.

54. Cowan CM, Roskams AJ. Apoptosis in the mature and developing olfactory neuroepithelium. Microsc Res Tech. 2002 Aug 1;58(3):204-15.

55. Conley DB, Robinson AM, Shinners MJ, Kern RC. Age-Related Olfactory Dysfunction: Cellular and Molecular Characterization in the Rat. OceanSide Publications, Inc;
Robert Pellegrino

Interdisciplinary Center on Smell and

Taste

Department of Otorhinolaryngology

TU Dresden

Fetscherstrasse 74

01307 Dresden

Germany

E-mail: pellegrino.robert@gmail.com

\section{ADVERTISEMENT}

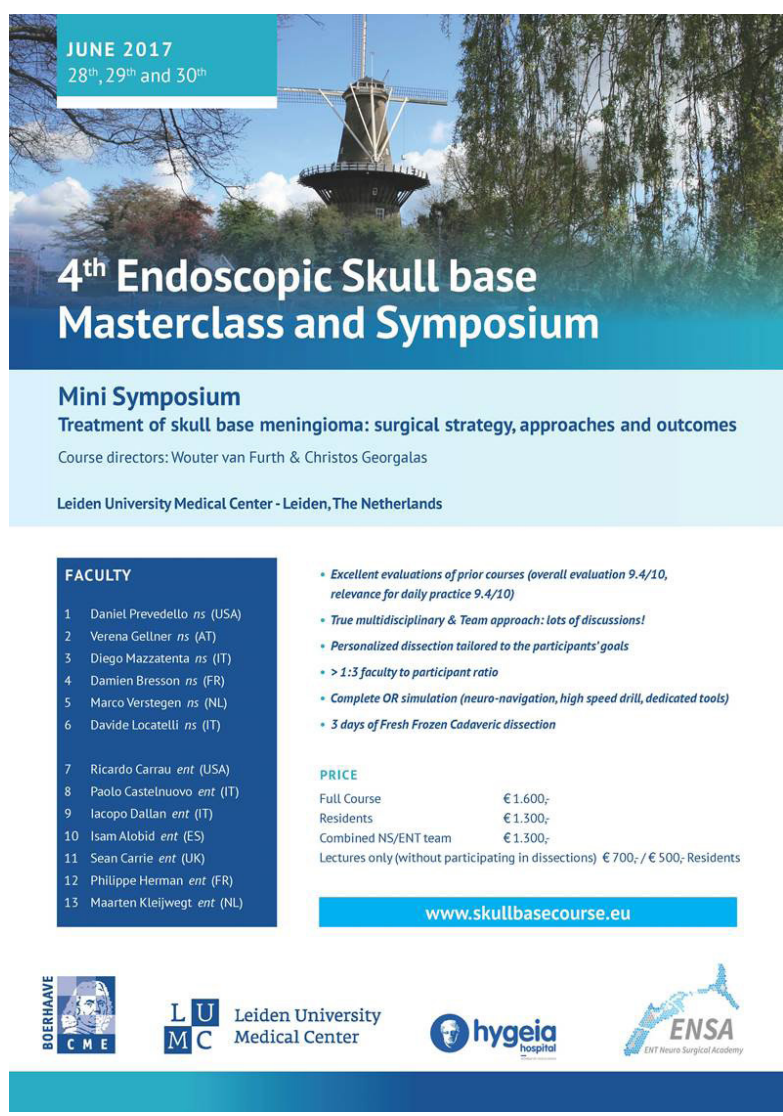

